\title{
Universiteit
}

Leiden

The Netherlands

\section{Introduction: directions in sociopragmatics}

Haugh, M.; Kádár, D.Z.; Terkourafi, M.

\section{Citation}

Haugh, M., Kádár, D. Z., \& Terkourafi, M. (2021). Introduction: directions in sociopragmatics. In Cambridge Handbooks in Language and Linguistics (pp. 1-12). Cambridge: Cambridge University Press.

doi:10.1017/9781108954105.001

Version:

Publisher's Version

License:

Licensed under Article 25fa Copyright Act/Law (Amendment Taverne)

Downloaded from: $\quad$ https://hdl.handle.net/1887/3223056

Note: To cite this publication please use the final published version (if applicable). 


\section{1}

\section{Introduction}

\section{Directions in Sociopragmatics}

Michael Haugh, Dániel Z. Kádár and Marina Terkourafi

\subsection{The Genesis of the Present Handbook}

Pragmatics is generally defined as the study of the use of language. It is a rapidly growing field that is associated with numerous international conferences, more than a dozen specialist journals, and a number of book series with international publishers. It is thus not surprising that there are already a number of one-volume handbooks of pragmatics on the market, as well as two well-established handbook series. ${ }^{1}$ What is perhaps surprising, however, is that in the case of one-volume handbooks of pragmatics, topics in linguistic and cognitive pragmatics still seem to predominate. The apparent preference for such topics in single-volume handbooks can be explained, in part, by the philosophical origins of pragmatics as a discipline in the 1970s. Pragmatics as a field, however, has expanded significantly beyond those origins.

This was recognized early on by Leech (1983) and Thomas (1983), who proposed a distinction be made between pragmalinguistics (the study of the meanings conveyed by different linguistic forms and strategies) and sociopragmatics (the study of users' perceptions of the contextual factors, including perceived sociocultural norms, underlying the interpretation and performance of communicative acts as (in)appropriate). Both of these areas typically address topics, such as implicature, speech acts, deixis, politeness and so on, albeit from a more cognitive, linguistic or social perspective. The latter, however, adds further topics to the mix, including face, relationships, identities, power, emotion, stance and humour, to mention but few. A glance through recent issues of leading journals in the field shows that many of the articles published are concerned with topics from this second

\footnotetext{
The latter include the Handbook of Pragmatics Online published by John Benjamins (ed. by Őstman and Verschueren, since 1995) and the Handbooks of Pragmatics series published by Mouton de Gruyter (ed. by Bublitz et al., since 2011).
} 
set suggesting that they are active loci of research in which students should also be trained. Yet, questions of linguistic and cognitive pragmatics have generally received the lion's share of attention in previous handbooks. ${ }^{2}$

In making this point we are in no way intending to diminish the valuable contribution that the currently available handbooks of pragmatics have made to the field. They are important and clearly vital for advancing debate and understanding pragmatics scholarship. There is, however, in our view, also room for further elaboration of other topics that figure prominently in pragmatics research. Indeed, this handbook was conceived to complement the coverage of linguistic and cognitive aspects of pragmatics in the previously published Cambridge Handbook of Pragmatics (Allan and Jasczcolt 2012). We thus initially started out by identifying areas of pragmatics that we felt had not received enough attention in extant handbooks of pragmatics. In other words, we started out with a 'negative' definition of sociopragmatics as areas of pragmatics that were not covered in previous handbooks. However, it quickly became apparent to us that approaching the design of the handbook in this way could only get us so far. A different approach was needed.

A handbook can attempt to do two things. It can represent an attempt to systematize a field and lay out key elements of its orthodoxy. The aim is to organize and define the field in question. Alternatively, a handbook can represent an attempt to chart out a field of inquiry in order to stimulate further dialogue and showcase its richness. The aim in the latter case is thus not to codify or prescribe, but rather to lay out the various directions in which a field has been developing. This handbook falls clearly into this second camp. Our goal with it has been to map the territory occupied by sociopragmatics, a field which has been developing a distinct identity in its own right 'in the wild', so to speak. That said, charting the boundaries - or, rather, the outer edges - of a field is also a work in progress. As the field continues to grow, we expect that new topics will be added to it. We therefore caution that this is only a first attempt at representing the richness of sociopragmatic research and, indeed, welcome future works that will expand the field in new, possibly unanticipated directions.

In the following section, we move to consider more carefully the scope of sociopragmatics, and how it can be framed in different, albeit largely complementary ways. We then offer, in Section 3, an overview of the contents of the handbook proper, explaining how we have brought together a range of different research areas, topics and approaches under the

\footnotetext{
2 In the most extreme case, there is not one single chapter devoted to topics in sociopragmatics (Horn and Ward 2004), something which generated some controversy at the time (Mey 2005). But even when there have been attempts to strike some kind of balance, chapters focusing on topics in sociopragmatics remain few and far between. For example, in Allan and Jaszczolt (2012) there are just two chapters out of 31 that deal directly with issues in sociopragmatics, while in Huang (2017) only four chapters out of 30 focus on sociopragmatics. There is greater balance in Barron et al. (2017), but the depth of coverage of sociopragmatics is limited due to the sheer breadth of topics in pragmatics a general handbook needs to cover.
} 
umbrella of 'sociopragmatics'. We conclude with a brief discussion of the place of sociopragmatics with respect to the broader field of pragmatics.

\subsection{The Scope of Sociopragmatics}

This volume is, to our knowledge, the first handbook of sociopragmatics. However, since our aim has not been to codify or prescribe, but rather to chart existing and new directions, we have taken a broadly inclusive and open-ended approach to what we consider sociopragmatics to be. Some of the chapters in this handbook offer explicit definitions of sociopragmatics, others do so only implicitly, remaining largely tacit on the matter. Our preference is for an organic, bottom-up conceptualization of the field to emerge through researchers engaging with this collection of chapters, rather than trying to advocate for a one-size-fits-all definition of sociopragmatics. This preference is also rooted in the observation that, while there is clearly an overall direction in which the field is moving, different shades and nuances emerge when one starts to consider seriously the scope of 'sociopragmatics' - what the field encompasses and its theoretical and methodological underpinnings.

One way of scoping out sociopragmatics is to examine its disciplinary antecedents. The roots of pragmatics generally lie in the work of ordinary language philosophers (Austin, Grice, Searle, and the later Wittgenstein) and attempts to theorize the abstract, context-general principles by which we use language to mean and do things in the world. Attention to the role of social variables with respect to the operation of such principles featured very early on in this work as well (e.g. Austin [1962] 1975; Brown and Gilman 1960; Lakoff 1973; Leech 1977). This places sociopragmatics at the intersection of linguistic and social concerns, which can be approached from multiple perspectives, as shown in Figure 1.1.

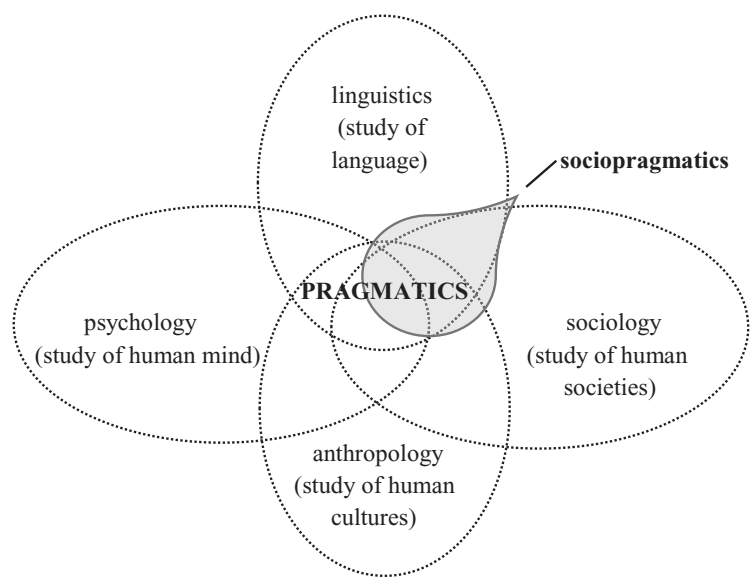

Figure 1.1 Sociopragmatics at the intersection of linguistics and sociology. Adapted from Haugh and Culpeper (2018: 220). 
From this very broad perspective, sociopragmatics focuses on the role of social conditions and variables in determining the use of language to mean and do things in the world. It thus lies at the intersection of linguistics and sociology, a space also traditionally occupied by sociolinguistics, while also taking in aspects of anthropology and (social) psychology.

A first pass at delimiting the scope of this rather broad conceptualization of sociopragmatics is to follow the original distinction between pragmalinguistics and sociopragmatics as distinct avenues of research, which fall under, but are somewhat separate from, general pragmatics, as argued by Leech (1983). On this view, pragmalinguistics examines the relationship between forms and the meanings they can express, while sociopragmatics examines the distribution of form/meaning pairs in different contexts and the extent to which they are appropriate to those contexts. The latter is most closely aligned with sociology, as represented in Figure 1.2, echoing the view of sociopragmatics as lying at the intersection of linguistics and sociology we saw in Figure 1.1.

As the account of sociopragmatics developed by Leech (1983) and Thomas (1983) is arguably rather under-developed, particularly with respect to the role of culture in the production and interpretation of pragmatic meanings (Chapter 2), an important goal of the present handbook is to flesh this out more fully and offer grounds to develop this further. This has already been done in some quarters of sociopragmatics, particularly in cross-cultural and intercultural pragmatics (Chapter 34) and second language or interlanguage pragmatics (Chapter 35).

A second view is to regard sociopragmatics as arising from a fusion between (classical) pragmatics and (classical) sociolinguistics, as represented in Figure 1.3. Holmes (2018) most clearly articulates this view. She describes pragmatics as involving the study of the use of language in context, specifically, "how individuals use linguistic resources to produce and interpret meaning in interaction, and sometimes to change relationships" (11). Sociolinguistics, on the other hand, involves the study of

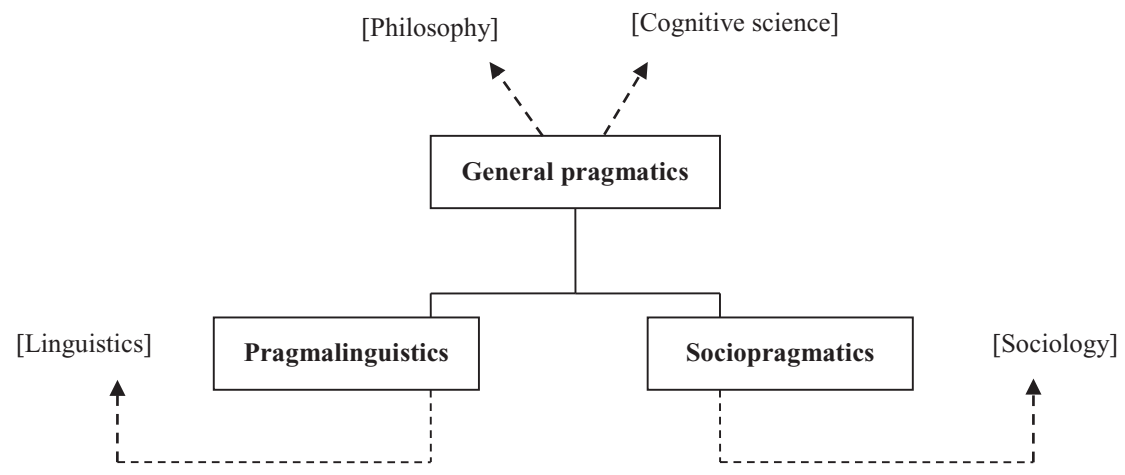

Figure 1.2 General pragmatics, pragmalinguistics and sociopragmatics. Adapted from Leech (1983: 11). 


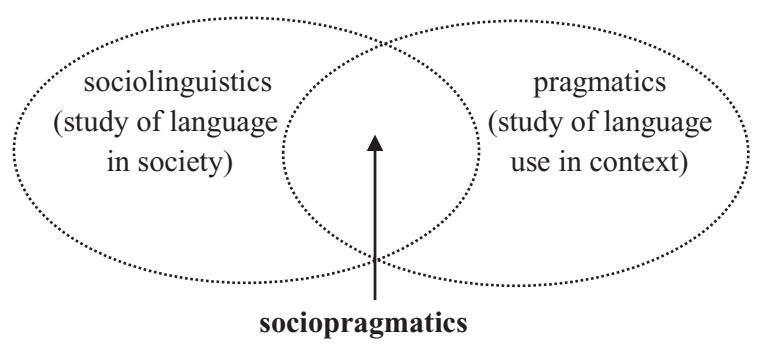

Figure 1.3 Sociopragmatics at the intersection of sociolinguistics and pragmatics.

language in society, resulting in descriptions of variation in the linguistic resources available in speech communities, and "systematic accounts of how social variables influence linguistic choices from among those resources" (Holmes 2018: 11). On this view, sociopragmatics involves "identifying and analysing evidence for societal norms and how they are subscribed to and contested" (Holmes 2018: 15).

This view draws particular attention to the importance of norms and interaction, in addition to the already well-attested focus on users and the social dimension of language use seen in the two approaches above. This approach also tends to privilege discourse analytic approaches, such as interactional sociolinguistics.

A final possibility is to take our lead from published articles and volumes over the past couple of decades and present a bottom-up view of what sociopragmatics encompasses based on what people have analysed. This leads us to adopt, in this handbook, social, interactional and normative dimensions of language use as the three key anchors of sociopragmatic research.

A focus on the social side of pragmatics, in contrast to its linguistic side, means we are interested in speakers first and utterances second. This means engaging with the subjectivities, social identities and individual positionings of speakers as they arise in interaction with others: speakers are not treated as isolated individuals (as they might in a processing account of individual cognition), but as members of various groups, with those membership(s) being attested and contested in interaction. It also means examining the intersection of language and sociocultural phenomena, that is, teasing out the processes by which language use impacts on and interfaces with the social world. There are, of course, significant differences in the ways in which the "social" (or sociocultural) is theorized and operationalized in sociopragmatic research. For instance, a sociolinguistic view of the social dimension of language use tends to focus on social and cultural variables (Labov 1966; Chapter 10), while a sociological view tends to conceptualize it through the lens of the social or moral order (Goffman 1969; Garfinkel 1967; see also Chapter 19).

A focus on interaction means we are interested in discourse first and utterances second. The primary aim is to examine the production and 
interpretation of meaning in situated contexts, and the choices of speakers and recipients in the accomplishment of those meanings. The emphasis is on both local and meso-level contexts (i.e. what are variously called activity types, speech events, genres and so on - see Chapter 11). There are, of course, significant differences in the ways in which "interaction" is theorized and operationalized in sociopragmatic research. For instance, a discourse analytic view tends to focus on the indexical properties of interaction (Silverstein 1976), while a conversation analytic view emphasizes the sequential properties of interaction (Sacks et al. 1974). As Arundale (Chapter 14) notes, different views of interaction impact the ways in which social elements of language use, such as relationships, are conceptualized. For this reason, it is difficult to analyse social dimensions of language use without considering interactional aspects, and vice versa.

Finally, a focus on the normative side of pragmatics draws attention to the ways in which language use is both constituted through and constitutive of norms, that is, common or preferred ways of using language. A key focus in sociopragmatics is on evaluation and issues of '(in)appropriateness' or '(un)acceptability' of certain forms of interactional behaviour within and across groups, as well as on the maintenance, exploitation and contestation of those norms within and across groups. Once again there are, of course, significant differences in the ways in which "norms" are theorized and operationalized in sociopragmatic research. For instance, in some approaches the focus is primarily on statistical norms, that is, examining what is most frequently done, or what are also variously called empirical or descriptive norms of language use. In other approaches, the focus is primarily on moral norms, that is, examining how people talk about what should be done, or what are also variously called injunctive or prescriptive norms (Deutsch and Gerard 1955). A mark of sociopragmatic research is that it attempts to elucidate the relationship between the two (see also Chapters 9 and 16), and for this reason it is difficult to analyse social and interactional dimensions of language use without also considering its normative dimensions, and vice versa.

The view of sociopragmatics we have sketched above is represented in Figure 1.4. We caution that this representation is intended to be neither exhaustive nor prescriptive. Instead, our aim is simply to draw attention to some common threads that can be found across research in sociopragmatics to date. We also note that these three anchors of sociopragmatics are broadly compatible with the two main approaches to delimiting sociopragmatics we discussed earlier in this section. This is important because all of these understandings of sociopragmatics are represented across the chapters in this volume.

We hasten to add that this emphasis on analytical anchors, and the fact that there is no one grand theory of sociopragmatics, should not be taken to mean that the field itself is atheoretical. Nevertheless, we do see a need for 


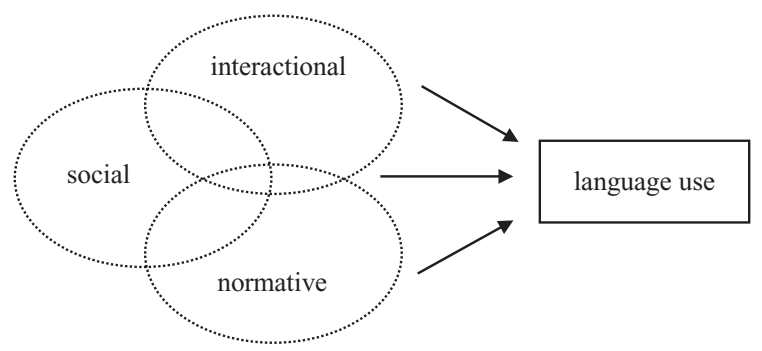

Figure 1.4 Key anchors of sociopragmatics.

more explicit theorization in sociopragmatics. As the discussion above suggests, and the chapters in this volume attest, many theoretical developments in sociopragmatics have built on concepts and theories borrowed from cognate disciplines. Perhaps the time is now ripe to move from empirical studies to theorization, developing theories which build on other areas but nevertheless address the three key anchors of sociopragmatics we highlight here, thus treating sociopragmatics as an area requiring theorization in its own right.

Drawing attention to the social, interactional and normative ends of pragmatics also makes more pronounced the need to extend our research in pragmatics to a much greater range of languages than has traditionally been the case. There are more than 6,000 languages spoken in the world, although many of these are currently endangered. By extending sociopragmatics research to a broader range of the world's languages we can test the theoretical and conceptual apparatus that has been developed, contributing to our understanding of not only what makes each language and culture unique, but importantly what also lies in common and ultimately unites us all.

\subsection{Overview}

This handbook is aimed at both students who have studied linguistics or pragmatics and need an up-to-date account of the field, as well as researchers wishing to gain an advanced overview of different areas within sociopragmatics. The contributors, who were all chosen for their specific expertise and contributions to sociopragmatics, were asked to provide accessible summaries of key concepts, issues and ongoing research on significant areas within sociopragmatics. Many of the chapters also feature original case studies that illustrate how one can undertake research in sociopragmatics. As the purpose of this handbook is to showcase research and directions in sociopragmatics, it is expected that readers will not necessarily review the book from cover to cover, but will rather consult specific chapters depending on their needs and areas of interest. Efforts have therefore been made to cross-reference other chapters 
where relevant in order to guide readers and assist them in expanding their knowledge of the field.

The handbook is divided into three parts: "Fundamentals" (Part I), "Topics and Settings" (Part II) and "Approaches and Methods" (Part III). Notably, while some of the chapters cover areas that are highly developed, and so involve summarizing a fairly large extant literature in a way that speaks to the specific concerns of sociopragmatics (e.g. implicature, politeness and impoliteness, cross-cultural pragmatics), other chapters break new ground, identifying gaps and areas that are ripe for further study (e.g. affect and emotion, morality, CA and sociopragmatics). In both cases, however, the emphasis is on illustrating key concepts and issues through data, exemplifying the significant emphasis that is placed on empirical analysis in the field.

Part I, "Fundamentals", offers coverage of some of the key theoretical and conceptual tools drawn upon in sociopragmatic analyses. The emphasis in this part is on introducing these concepts, while the next two parts exemplify their application to the study of particular phenomena and settings. Both foundational notions in pragmatics (inference and implicature, speaker's meaning, speech acts and social actions, conventions), as well as notions originally developed in other disciplines including sociology (footing), anthropology (reflexivity), and sociolinguistics (communities of practice, stance), are featured in this part, highlighting from the outset the interdisciplinary origins of the field. At the same time, their relevance to sociopragmatics is highlighted through case studies that are intended to show how these concepts can be put to use as tools for sociopragmatic research. Although most of the examples are drawn from (varieties of) English, examples from other languages, such as German and Finnish, are also discussed, setting the tone for the description of multiple varieties and languages, a thread that runs throughout this handbook. Indeed, as we observed earlier, we see the presence of multiple varieties and languages as serving not only a descriptive but also a theoretical goal in sociopragmatics, as it can serve to propel theory development in the field. As such, it has been our distinct goal in this handbook to be inclusive, not only with respect to theoretical and topical perspectives, but also with respect to the languages and language varieties represented.

The topics covered in Part II of this handbook are centred on the interactional formation and negotiation of interpersonal relationships, an area that has continued to remain at the forefront of sociopragmatic research over many decades. The "interpersonal" focus of sociopragmatics (Leech 1983: 79) traditionally consists of research on either types of interpersonal behaviour, such as politeness and humour, or on socio-psychological and societal factors that both underpin and are accomplished through interpersonal behaviour, such as identity and face. Part II, "Topics and Settings", brings this research together by addressing (1) key topics in sociopragmatics, spanning (im)politeness and humour through to morality 
and power; and (2) key settings of sociopragmatic research, spanning digitally mediated and multimodal forms of communication through to workplaces, service encounters and discourse in translation. Although the chapters in this part include well-studied topics, such as face and (im)politeness, and less-studied ones (at least from a sociopragmatics angle), such as emotion, morality and power, we are well aware that the current selection is far from exhaustive. Indeed, it could not be, as researchers continue to approach new topics from a sociopragmatic angle on a regular basis. Our goal here was on achieving representativeness rather than exhaustiveness. Our selection of key settings thus focuses on the most popular and widely studied contexts of sociopragmatic research to date, including multimodal communication, digitally-mediated communication, workplace and institutional discourse, service encounters and discourse, argumentative, political and legal discourse, and discourse in translation. What makes research on these settings particularly relevant to the reader, in our view, is their relevance for our ordinary lives. Along with English, the examples and analyses in this part draw on various other languages, including Arabic, Chinese, Korean and Spanish. As noted earlier, this demonstrates a long-term aspiration of the field to describe the sociopragmatics of languages around the world.

The final part of the handbook, Part III, “Approaches and Methods", features a number of key areas that contribute to sociopragmatics, spanning well-established ones, such as second language pragmatics and cross-cultural/intercultural pragmatics through to emerging ones, such as CA-informed sociopragmatics and corpus sociopragmatics. Many of these represent areas of research in their own right, with their own distinct sets of methods and theoretical commitments. In other words, we are not seeing these necessarily as sub-fields of sociopragmatics, but rather as areas that make important contributions to the range of research approaches and methods that are used in sociopragmatics. These range from an explicit commitment to the use of multiple methods (e.g. interpersonal pragmatics; historical sociopragmatics; variational pragmatics), through to a commitment to a particular, clearly circumscribed set of methods (e.g. corpus pragmatics; CA), although a common touch point in terms of methodology across these different approaches is the frequent use of various forms of discourse analysis. Other chapters also draw attention to the need to broaden the scope of sociopragmatics, to be inclusive of different cultural perspectives (e.g. emancipatory pragmatics; cross-cultural and intercultural pragmatics). Overall, the chapters in this part collectively demonstrate the wide range of approaches and methods that are drawn upon in sociopragmatics research, which, once again, draws attention to the necessarily interdisciplinary theoretical and methodological outlook of the field.

We admit, however, that while we have aimed to be inclusive and openended in our coverage, this is not necessarily complete. We have only been 
able to include passing reference to important topics or approaches that are potentially relevant to sociopragmatics, such as social cognition or ethnopragmatics, while other areas that we think are of considerable importance, such as the sociopragmatics of endangered languages, still remain to be adequately charted, and so were not included. In the end, some hard choices had to be made in order to keep the overall length of the volume manageable. We anticipate that in future handbooks, the new directions currently being developed will inevitably result in new topics, settings and approaches also being explored. We look forward to seeing those seeds come to fruition.

\subsection{Closing Thoughts}

The present handbook began as an attempt to address what we felt to be a significant gap in relation to the coverage of topics in extant handbooks of pragmatics, especially when viewed against the background of research published in this field. However, we would like to stress that, while naming a field through the development of a handbook can inadvertently emphasize points of difference over points of commonality, we are all interested in language use. As such, our view is that more, not less, dialogue with researchers in linguistic and cognitive pragmatics is what is needed. Pragmatics involves not only social, but also cognitive and linguistic perspectives on language use. The superordinate field of pragmatics will only progress when we find ways to bring these perspectives together (perhaps in new ways). Bringing together different disciplinary perspectives in productive ways inevitably begins from mutual understanding. In articulating what is encompassed by sociopragmatics through this handbook, and complementing previous handbooks that cover the more linguistic and cognitive end of pragmatics, we are attempting to put in place solid grounds for such dialogue to proceed. By the time our task was completed, we felt ourselves that we had learnt a lot from bringing together the various strands of research in sociopragmatics under a single 'home'. We hope that readers of this volume will share in this feeling and that this handbook will offer much needed coherence to this corner of pragmatics, as well as push the field forward through the contributions of leading scholars featured in its pages.

\section{References}

Allan, K. and Jaszczolt, K. M. (eds.). (2012). The Cambridge Handbook of Pragmatics. Cambridge: Cambridge University Press.

Austin, J. L. ([1962] 1975). How to Do Things with Words. 2nd ed. Edited by J. O. Urmson and M. Sbisà. Cambridge, MA: Harvard University Press. 
Barron, A., Grundy, P. and Gu, Y. (eds.). (2017). The Routledge Handbook of Pragmatics. London: Routledge.

Brown, R. and Gilman, A. (1960). The pronouns of power and solidarity. In T. A. Sebeok, ed., Style in Language. Cambridge, MA: MIT Press, pp. 253-76.

Brown, P. and Levinson, S. C. (1987). Politeness: Some Universals in Language Usage. Cambridge: Cambridge University Press.

Bublitz, W., Jucker, A. H. and Schneider, K. P. (eds.). (2011-). Mouton Handbooks in Pragmatics. Berlin: Mouton de Gruyter.

Deutsch, M. and Gerard, H. (1955). A study of normative and informational social influences upon individual judgment. The Journal of Abnormal and Social Psychology, 51, 629-36.

Garfinkel, H. (1967). Studies in Ethnomethdology. Englewood Cliffs, NJ: Prentice Hall.

Goffman, E. (1969). The Presentation of Self in Everyday Life. New York: Doubleday.

Haugh, M. and Culpeper, J. (2018). Integrative pragmatics and (im)politeness theory. In C. Ilie and N. R. Norrick, eds., Pragmatics and Its Interfaces. Amsterdam: John Benjamins, pp. 213-39.

Haugh, M., Kadar, D. and Mills, S. (2013). Interpersonal pragmatics: Issues and debates. Journal of Pragmatics, 58, 1-11.

Holmes, J. (2018). Sociolinguistics vs. pragmatics. In C. Ilie and N. R. Norrick, eds., Pragmatics and Its Interfaces. Amsterdam: John Benjamins, pp. 11-32.

Horn, L. and Ward, G. (eds.). (2004). Handbook of Pragmatics. Oxford: Blackwell.

Huang, Yan (ed.). (2017). The Oxford Handbook of Pragmatics. Oxford: Oxford University Press.

Labov, W. (1966). The Social Stratification of English in New York City. Cambridge: Cambridge University Press.

Lakoff, R. (1973). The logic of politeness; or, minding your p's and q's'. Papers from the Ninth Regional Meeting of the Chicago Linguistic Society, 8, 292-305.

Leech, G. (1977). Language and tact (Series A, Paper No. 46). Linguistic Agency University of Trier.

Leech, G. (1983). Principles of Pragmatics. London: Longman.

Marmaridou, S. (2011). Pragmalinguistics and sociopragmatics. In W. Bublitz and N. R. Norrick, eds., Foundations of Pragmatics. Berlin: Mouton de Gruyter, pp. 77-106.

Mey, J. (2005). What is in a (hand)book? Reflections on a recent compilation: Review of Horn, R. Laurence and G. Ward (eds.), The handbook of pragmatics. Intercultural Pragmatics, 2, 347-58.

Mey, J. L. (2012). Societal pragmatics. In C. A. Chapelle, ed., The Encyclopedia of Applied Linguistics. Chichester: John Wiley, pp. 1-6.

Őstman, J.-O. and Verschueren, J. (1995-). Handbook of Pragmatics Online. Amsterdam: John Benjamins. 
Sacks, H., Schegloff, E. and Jefferson, G. (1974). A simplest systematics for the organization of turn-taking for conversation. Language, 50, 696-735.

Silverstein, M. (1976). Shifters, linguistic categories and cultural description. In K. Basso, H. Selby and A. Henry, eds., Meaning in Anthropology. Albuquerque: University of New Mexico Press, pp. 11-55.

Thomas, J. (1983). Cross-cultural pragmatic failure. Applied Linguistics, 4(2), 91-112. 